\title{
An experimental investigation on the efficiency of snail entry in vortex tube fed low inlet air pressure to reduce temperature of low pressure air
}

\author{
Wasan Naksanee ${ }^{1}$, Ratthasak Prommas ${ }^{2 *}$ \\ ${ }^{1}$ Rattanakosin College for Sustainable Energy and Environment (RCSEE), Rajamangala University of Technology \\ Rattanakosin, 96 moo3 Puthamonthon Sai 5, Salaya, Puthamonthon, Nakhon Pathom 73170, Thailand \\ ${ }^{2}$ Mechanical Engineering, Faculty of Engineering, Rajamangala University of Technology Rattanakosin, 96 moo3 \\ Puthamonthon Sai 5, Salaya, Puthamonthon, Nakhon Pathom, 73170, Thailand
}

Corresponding Author Email: ratthasak.pro@rmutr.ac.th

https://doi.org/10.18280/ijht.360409

Received: 30 April 2018

Accepted: 10 December 2018

\section{Keywords:}

snail entry, Vortex tube, Inlet air pressure

\begin{abstract}
This study seeks to explain the use of low pressure inlet air to serve as a cooling agent to lower the discharge temperature of hot air by employing a vortex tube which has a snail nozzle designed specifically to achieve this objective. A series of tests were performed using various snail nozzles with entries of (n) 4-8 at a pressures of 1, 2, and 3 bar, using a counter-flow vortex tube with inner diameters of $10,12,14,16$, and $18 \mathrm{~mm}$. During the course of the experiment it was possible to vary the maximum temperature within the vortex as well as the energy separation, by making adjustments to the inlet air stream. It was thus possible for this stream to leave the vortex tube at a temperature level equal to just $40 \%$ of the intake mass flow. The vortex tube thus exhibited a cooling capacity capable of taking an inlet temperature at the snail nozzle of $25^{\circ} \mathrm{C}$, and reducing this to a low of $-20.2{ }^{\circ} \mathrm{C}$. The largest observed change in air temperature amounting to $45.2^{\circ} \mathrm{C}$, was achieved with a vortex tube diameter of $16 \mathrm{~mm}$ and the use of a 6-snail nozzle. Cooling efficiency could be calculated to provide $\eta$ max cooling $41.6 \%$.
\end{abstract}

\section{INTRODUCTION}

Vortex tubes are simple machines which can turn the pressurized air which enters the tube into streams of both hot and cold air at the same time [1]. It was first discovered by the Frenchman George J. Ranque [2], during the course of his work with air compressors and vortex pumps, although this was not the objective of his experiments. He found that when the air intake nozzle is shaped so as to force the air into a Tshaped cylinder which has nozzles around the middle of the tube close to the inlet, the air stream can be separated into flows of different temperatures. One exit releases the stream of hot air, while the opposite end serves as the cold stream outlet. Temperature separation or energy separation begins in the vortex tube with the tangential injection of the compressed air flow. This leads to a higher gas temperature of the inlet gas near the outer region of the tube than at its core. There are two kinds of vortex tube: one with a counter-current flow, and one with a con-current flow, also known as parallel flow. The most widely-used version in industrial settings is the countercurrent flow type, which causes hot and cold air streams to exit in opposite directions. The con-current flow type has the same exit direction of the cold air and the hot air but through separated outlets. The compressed air entry passes through nozzles around the tube radius near the entry. The air flow passing through the tube turns into a heavy swirling flow of high-speed velocities. This creates a centrifugal force directed away from the axis. Moreover, when the air is swirling inside the tube, it can be expanded and causes lower pressure along the axis line. The huge difference of the flow rates between the axial region and the wall region develops a kinetic energy reaction that transfers the lower temperature axial region to the higher temperature around the wall region. The effect is termed as the thermal separation phenomenon. In addition to the cold orifice structure of the tube, control valves were installed around the hot air exit. The low temperature air flow from the axis region reverses to escape at the orifice in the core region and passes through the cold outlet at the opposite direction of the hot cold outlet as in the illustration. There are a few advantages for having a vortex tube. Its application permits the use of free air as a substance in industrial processes with the air being non-toxic, favorable to the environment and as a consequence countering the effect of greenhouse gas, which is the main factor leading to global warming. The vortex tube is usually lightweight in design with no moving parts and no need for maintenance, convenient for usage and durable; and portable. These benefits make the vortex tube advantageous for public interest and employed in industrial processes. One way the vortex tube is sometimes used is to provide cooling when items are undergoing a cutting process on the production line to prevent heat damage [3]. The result of this application shows that the vortex tube's performance is equal to that of a traditional cooling system composed of chemical elements such as Chlorine, Sulphur and Phosphorus, which are harmful to the environment.

The name of the vortex tube refers to the nature of the air flow within its confines, although it has also been named the Ranque-Hilsch vortex tube in memory of its creators. It has since attracted considerable attention from researchers seeking to explain the thermal separation phenomenon which occurs within. Practically, the effective use of the vortex tube to describe the thermal separation phenomenon revolves around 
thermodynamic theory, heat transfer, and the mechanics of air flow. Although there are a lot of previous studies about the phenomenon, there still is no consensus on the exact theory as a basis to describe the complex behavior that occurs inside the tube. Therefore, more research on the topic is needed.

The vortex tube has a number of interesting practical applications, such as providing the cooling system for the control room that houses electronic components which govern electrical circuits and systems. They can also be used in industrial settings where metalwork processes generate excessive levels of heat, such as cutting or drilling, so that the metal pieces being worked must be simultaneously cooled to prevent heat or spark damage. The vortex tube can help reduce pollution from the coolant molecules which are large and difficult to deteriorate. Hence, the vortex tube can be referred as an environmental-friendly device.

The work of Eiamsa-ard [4] showed that the vortex tube is able to generate both hot and cold air upon compression of the air to 2-5 times that found at the inlet. This air passes tangentially through the tube in the absence of coolants, and starts to swirl strongly within the tube. The core region temperature falls below that of the area around the entry, causing hot and cold streams to separate. Cold air from the core will then pass via the opposite side of the valves which control the flow. In contrast, the hot air found at the walls of the tube will pass out on the same side as the control valves. The vortex tube generates hot and cold air streams via tangential velocities within the tube when the flow rate falls between 150 and $250 \mathrm{~m} / \mathrm{s}$, while at higher speeds it will reverse. Near the wall, the air temperature is hot, while the flow rate is low; conversely, the core of the tube sees low temperatures. A study of three dimensional heat transfers and air flow within the tube was conducted by Pankasikorn [5] who applied the Finite Volume Method and Turbulence Model. That study comprised two stages; the first sought to develop a suitable application for CFD software which would match or exceed the outcomes from earlier work. The aims of the study, however, emphasized the backward-facing step and the interior flow of a vortex stove which mimics that found within a vortex tube. The results from the first stage of that study were consistent with the reverse type of vortex tube. However, the result of the vortex stove type was high but the predictability of the flow rate was considerably not practical. Phase 2 research conduct dealt with the use of CFD software with the vortex tube of Parallel Flow and the vortex tube of the Counter-Flow. The result from Phase 2 by using Turbulence Model to measure the tangential velocities still could not effectively predict the Free Vortex. The result of the measurement of the temperature was higher than the experiment because of the limitation of the enthalpy value of the software. When comparing the cooling efficacies of both vortex types, it was found that the Parallel type had the higher cooling efficacy. Furthermore, a study examining the effects of vortex tube length, orifice diameter, substance type, and differing inlet air pressures upon the system cooling efficacy was carried out by Saidi and Valipour [6]. Their findings also revealed that inlet nozzles and the types of gas and the humidity levels had very high effects towards the reduction of the air temperature. Also, Promvonge and Eiamsa-ard [7] designed the snail entry which forced the air tangentially flowed into the vortex tube. Their finding supported that the snail entry could effectively reduce the air temperature and promoted the cooling efficacy.

As aforementioned, to reduce the temperature of hot air by means of a vortex tube which its temperature reduced required increasing wind speed. It affected the requirement to increase inlet air pressure. Furthermore, the design of snail entry could effectively reduce the air temperature by forcing closing the exit; therefore, it caused the vortex at the end of the last tube which is the weakness affecting the disorganizing wind flow. It is also the reason to increase air pressure resulting in the loss of energy. The error was fixed by developing snail entry that could effectively reduce the air temperature that forced swirling and increased the wind speed inside the tube. Moreover, the design included entry. The tangential velocities still could not effectively predict the free vortex that uses low air pressure to reduce the air temperature comparing the general use of pressure. In previous research from the aforementioned, the researchers put forward their attempts to improve the vortex tube capability, in terms of the length, types, airflow direction, and nozzle types. The success in reducing the air temperature was mostly found in the experiments with the air pressure of over 4 Bar. However, the air pressure that was less than 3 Bar was still found to be able to reduce the wind energy consumption. Therefore, the development of snail entry of the vortex tube to test the reverse airflow of tangential velocities of the tube can increase the air swirling rate inside the tube. The tangential velocities have high swirling rate and velocities. It then creates centrifugal force directed away from the axis. As the consequence, the expansion of airflow inside the tube reduced the pressure along the axial line of the tube. The difference of the air pressures between that in the core region and the region near the wall results in the kinetic energy from the core to the wall which results from the swirling within the cylindrical tube. This lowers the air temperature at the tube's core, causing the phenomenon of temperature separation. In summary, [8] the industrial sector can save energy through increased efficacy in the vortex tube, which is examined by experimentation with snail entry using low inlet air pressure to lower the air temperature.

\section{METHODOLOGY}

Regarding the vortex tube, when the inlet air pressures are compressed through the nozzles laid closing to the tube and the entry, it was found that the air flows through this tube will move heavily swirling with high speed, causing centrifugal force. Moreover, the flow expanded inside the tube resulting in low pressure at the core and causing the difference of speed flow in the core and the outer near the tube wall. It induced the transfer of kinetic energy from the core to the wall and it caused the low air temperature at the core while the air temperature at the wall area increased. This was called thermal separation or temperature separation. Besides, due to the tube structure had the cold orifice and the control valve had been installed at the end where the hot air was released and the low air temperature from the core reverse to the small open gab before flowing out of the vortex tube through the output which is not the same output of the hot air current. The thermal separation in the vortex tube it was discovered the length of vortex tube $(\mathrm{L} / \mathrm{D} \approx 20)$ [9] with a diameter of the nozzle $(\mathrm{d} / \mathrm{D}$ $\approx 1 / 3$ ) have the most efficiency. As a result, it is the key for designing vortex tube of this experiment.

Effective parameters used in the study: the most useful parameters in describing the operating attributes of the vortex tube cooling approach are the cold temperature difference and 
the cold stream mass ratio. It is possible to define the cold stream mass ration [10], or fraction, as:

$x_{c}=\frac{\dot{m}_{c}}{\dot{m}_{l}} ; x_{h}=\frac{m_{h}}{\dot{m}_{l}}$

where $\dot{m}_{c}$ denotes the rate of cold flow, $\dot{m}_{h}$ represents the rate of heat flow, and $\dot{m}_{l}$ denotes the rate of inlet flow rate [10]. The total temperature reduction, or cold temperature difference, shows the extent of the refrigeration as has the following definition:

$\Delta T_{c}=T_{i}-T_{c}$

where $T_{i}$ is the inlet stream temperature and $T_{c}$ is the cold stream temperature [11].

Efficiency of isentropic expansion: given that the isentropic expansion of an ideal gas occurs within the vortex tube, it is possible to calculate the isentropic cooling efficiency, $\eta$, by:

$\eta=\frac{\Delta T_{C}}{T_{i}-T_{S}} \times 100 ; T_{S}=\left[\left(\frac{P_{i}}{P_{a}}\right)^{(\gamma-1) / \gamma}-1\right]$

where $\eta$ is the cooling efficiency, $T_{s}$ represents the temperature following the isentropic expansion, $P_{a}$ denotes atmospheric pressure, and the specific heat ratio is shown by $\gamma$ [12].

Model: Earlier analysis demonstrated that the phenomenon of thermal separation stems from the way in which the mean kinetic energy is diffused in the vortex. At the tube axis, the temperatures are low both in total, and as static values, and these temperatures fall further nearing the cold exit or orifice of the vortex tube. The design of a vortex tube will have varying effects upon the way the mean kinetic energy is diffused, such that it is possible to design a vortex tube either to achieve maximum temperature separation, or simply to maximize the overall efficiency. When a specific pressure level is set, vortex tubes of differing design parameters are able to achieve identical outcomes in terms of temperature separation. However, when a design parameter has an influence upon the flow field, the vortex tube's performance will undoubtedly see an impact.
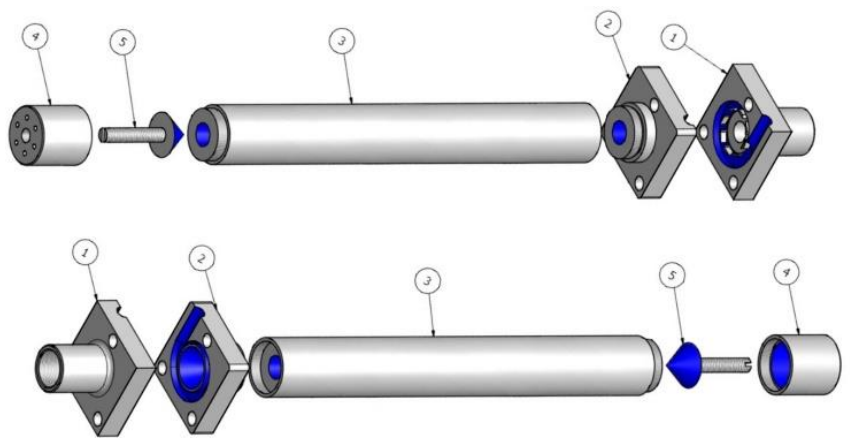

Figure 1. Model design snail nozzle entry in vortex tube

From Figure 1 it can be seen that vortex tube design takes into account a number of different tube parameters, including (1) special snail nozzle entry, (2) orifice diameter, (3) tube length, (4) hot tube length and (5) the shape of the cone valve.

Figure 2 reveals that earlier research demonstrated a snail with single inlet nozzle which was raised at the inlet to the counter-flow vortex tube, creating an increased swirl flow. This generated a greater reduction in cold air temperature compared to traditional nozzles based on tangential velocities. This study presents a particular enhancement of snail geometry, with the creation of a special snail entry of $3 \mathrm{~mm}$ diameter (d) and varying snail nozzle entry numbers (n) comprising 4, 5, 6, 7 or 8 inlet nozzles.

Table 1. Physiological parameters measured

\begin{tabular}{|c|c|}
\hline No. & Model design snail nozzle entry in vortex tube \\
\hline 1 & Special snail nozzle entry $(\mathrm{n})$ of $4,5,6,7$ and 8 \\
\hline 2 & The orifice tube (D)10,12,14,16,18 mm \\
\hline 3 & $\begin{array}{c}\text { Tube length (L) } 200 \mathrm{~mm} \text { with inside diameter cold } \\
\text { orifice }(\mathrm{d}) 6 \mathrm{~mm}\end{array}$ \\
\hline 4 & $\begin{array}{c}\text { Heat tube the hot gas flow rate at }\left(x_{h}\right) 0.6 \text { according to } \\
\text { the equation }(1)\end{array}$ \\
\hline 5 & $\begin{array}{c}\text { Shape of the cone valve. [13]. A cold gas flow rate of } \\
\left(x_{c}\right) 0.4 \text { of the flow rate for the inlet total mass is } \\
\text { produced from the current boundary conditions on the } \\
\text { basis of equation }(1) .\end{array}$ \\
\hline
\end{tabular}
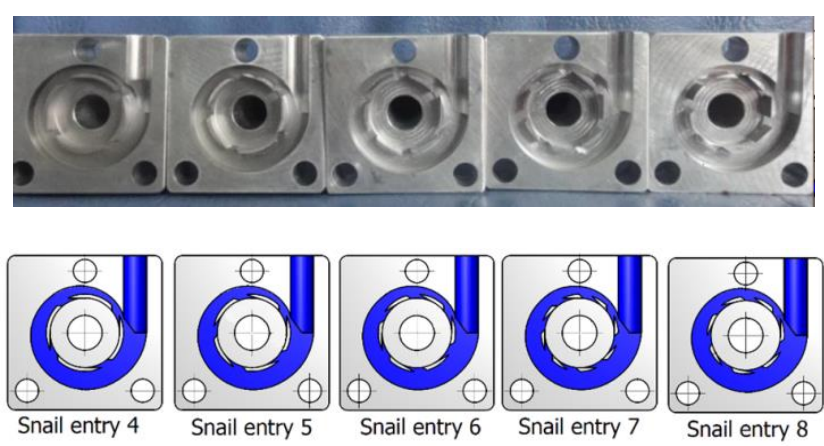

Figure 2. Special snail nozzle entry

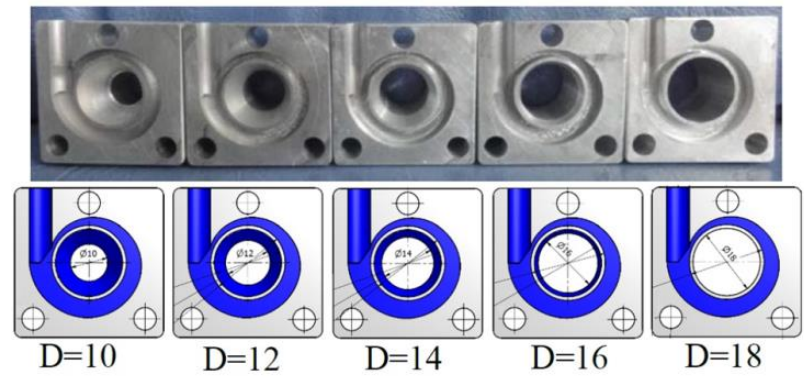

Figure 3. Diameters of the orifice tube

It can be observed in Figure. 3 that if the cold orifice is very small, the back pressure in the tube would be increased, with the direct consequence being a drop in temperature separation. However, if the cold orifice were much larger, air would be drawn directly from the inlet, thus reducing the tangential velocity close to the inlet, and also causing lower temperature separation. Similarly, when the inlet nozzle is small, the pressure in the nozzle will fall, and the tangential velocity created will be low. Once again, temperature separation is reduced. If the inlet nozzle is too large, the correct vortex flow will not occur; the mean kinetic energy diffusion drops and the temperature separation is once again low. It is important for the inlet nozzle to be placed near to the orifice in order to maximize tangential velocities in the region of the orifice. If the nozzle is located farther from the orifice, the tangential velocity, along with the temperature separation. Experimentation is performed to establish the characteristics of the counter-flow vortex tube with inner diameters (d) at the cold orifice of $10,12,14,16$, and $18 \mathrm{~mm}$. 
Simulation: the analysis, by using finite volume, to describe the characteristics of the internal flow of single snail entry vortex tube with 4 tangential inlet nozzles at 3 bar pressure is illustrated in $3 \mathrm{D}$ model. These characteristics include the speed and direction of flow, temperature, flow rate, and pressure. [14] In terms of the temperature separation of the inner tube, it is analyzed by using CFD solid works flow simulation as shown in the Figure 4 below.

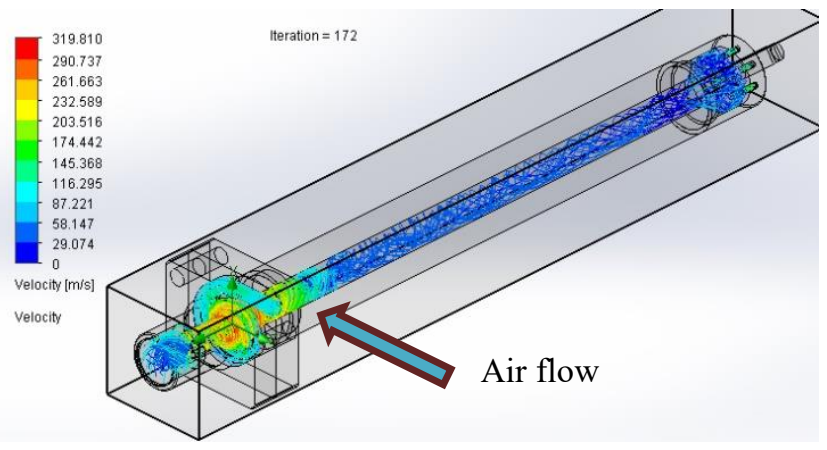

Figure 4. Simulation of swirl flow in snail entry vortex tube

Simulation equation of swirl flow created by solid works flow simulation, and controlled by flow equation, Continuity equation and Navier-Stokes equation can be described as follows:

Continuity equation

$\frac{\partial \bar{u}}{\partial x}+\frac{\partial \bar{v}}{\partial y}+\frac{\partial \bar{w}}{\partial z}=0$

Equation of momentum along $\mathrm{x}$ axis

$\bar{u} \frac{\partial \bar{u}}{\partial x}+\bar{v} \frac{\partial \bar{v}}{\partial y}+\bar{w} \frac{\partial \bar{w}}{\partial z}=-\frac{1}{\rho} \frac{\partial \bar{p}}{\partial x}+v \nabla^{2} \bar{u}-\frac{\partial}{\partial x}\left({\overline{u^{\prime}}}^{2}\right)-$

$\frac{\partial}{\partial y}\left(u^{\prime} v^{\prime}\right)-\frac{\partial}{\partial z}\left(\overline{u^{\prime}} \overline{w^{\prime}}\right)$

Equation of momentum along y axis

$\bar{u} \frac{\partial \bar{u}}{\partial x}+\bar{v} \frac{\partial \bar{v}}{\partial y}+\bar{w} \frac{\partial \bar{w}}{\partial z}=-\frac{1}{\rho} \frac{\partial \bar{p}}{\partial x}+v \nabla^{2} \bar{v}-\frac{\partial}{\partial x}\left(\overline{u^{\prime} v^{\prime}}\right)-$

$\frac{\partial}{\partial y}\left(v^{\prime 2}\right)-\frac{\partial}{\partial z}\left(\overline{v^{\prime}} \overline{w^{\prime}}\right)-\rho g$

Equation of momentum $\mathrm{z}$ axis

$\bar{u} \frac{\partial \bar{u}}{\partial x}+\bar{v} \frac{\partial \bar{v}}{\partial y}+\bar{w} \frac{\partial \bar{w}}{\partial z}=-\frac{1}{\rho} \frac{\partial \bar{p}}{\partial x}+v \nabla^{2} \bar{w}-\frac{\partial}{\partial x}\left(\overline{u^{\prime} w^{\prime}}\right)-$

$\frac{\partial}{\partial y}\left({\overline{v^{\prime}}}_{\overline{w^{\prime}}}\right)-\frac{\partial}{\partial z}\left({\overline{w^{\prime}}}^{2}\right)-\rho g$

Standard $\mathrm{k}-\varepsilon$ equation: $\mathrm{k}$ value and $\varepsilon$ value generated from heat transfer equation

$\frac{\partial(\rho k)}{\partial t}+\operatorname{div}(\rho k U)=\operatorname{div}\left[\frac{\mu_{1}}{\sigma_{k}} \operatorname{gradk}\right]+2 \mu_{t} E_{i j} E_{i j}-\rho \epsilon$

$\frac{\partial(\rho k)}{\partial t}+\operatorname{div}(\rho \varepsilon U)=\operatorname{div}\left[\frac{\mu_{1}}{\sigma_{\varepsilon}} \operatorname{gradk}\right]+C_{1 \varepsilon} \frac{\varepsilon}{k} 2 \mu_{t} E_{i j} E_{i j}-$

$C_{2 g} \rho \frac{\varepsilon^{2}}{k}$

Fixed set of values

$$
\mathrm{C}_{\mu}=0.09, \sigma_{\mathrm{k}}=1.00, \mathrm{c}_{1 \varepsilon}=1.44, \mathrm{C}_{2 \varepsilon}=1.92, \sigma_{\varepsilon}=1.3
$$

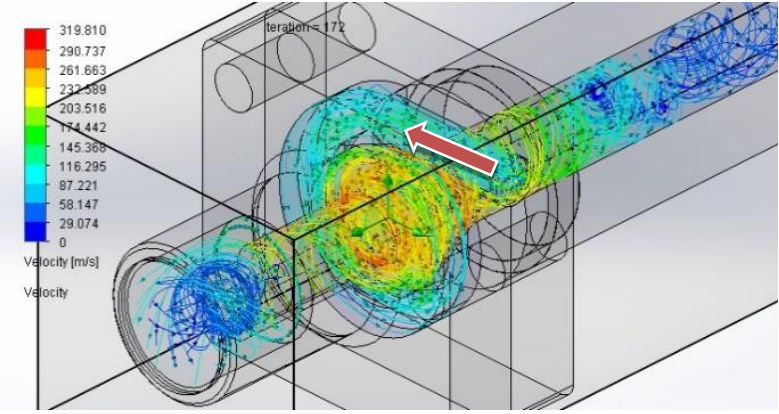

Figure 5. Simulation of velocities in single snail entry vortex tube with 4 tangential inlet nozzles

According to Figure. 5 simulating the speed of air flow inside the tube at 3 bar pressure, [15] the result shows that the air flow has no critical swirling turbulence and the velocity near the inner tube edge to the direction of the cold exit is at a maximum angular velocity of $290.810 \mathrm{~m} / \mathrm{s}$ according to the equation flow simulation, and controlled by flow equation, continuity equation and Navier-Stokes equation (4, 5, 6, 7, 8 and 9)

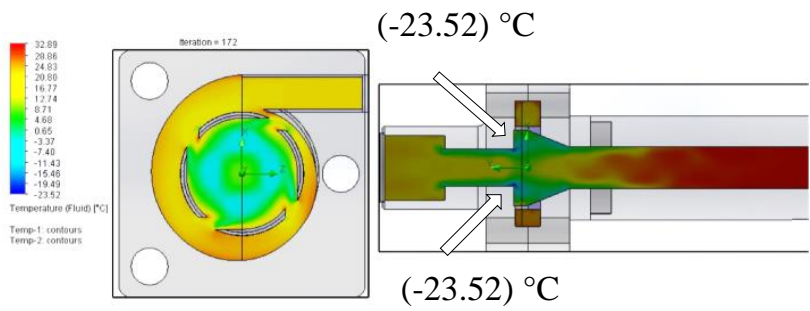

Figure 6. Simulation of temperature variations occurring inside the single snail entry vortex tube with 4 tangential inlet nozzles tube

The illustration imitates the temperature changes inside the tube, under the condition at 3 bar pressure, and at $25{ }^{\circ} \mathrm{C}$. The result reveals that the lowest temperature discovered near the tube edge to the cold exit is at positions highlighted by arrow in Figure.6, and that it is when the air transfer between the tube wall and the inner regions takes place that the increase in temperature will occur [16].

Methods: In the experimental tests, the parameters used to adjust the characteristics of the vortex tube models were capable of generating very low temperatures at the cold air exit. The minimum temperatures obtained came with inlet air pressure $P_{i} 1=1$ bar, $P_{i} 2=2$ bar, $P_{i} 3=3$ bar for the vortex generation. These parameters contained no crucial dimension which would create a unique outcome in terms of maximizing the temperature separation. Understanding the intricacies of the phenomenon of temperature separation allows the design of the vortex tube to be fine-tuned such that its parameters can be adjusted to create the required temperature separation. When the inlet characteristics are fixed and thus the supply pressure is fixed, the use of a tube with a small diameter can increase the back pressure and as a consequence the tangential velocity differential between the core and the walls would be lower on account of the lower specific volume of air. Meanwhile, the axial velocity at the core would be high, causing low kinetic energy diffusion and hence leading to low temperature separation. Conversely, increasing the tube diameter would have the effect of reducing the tangential velocities at the core and at the walls, once again lowering the mean kinetic energy diffusion and reducing the extent of 
temperature separation.

Measurement: Experimental setup to measure the

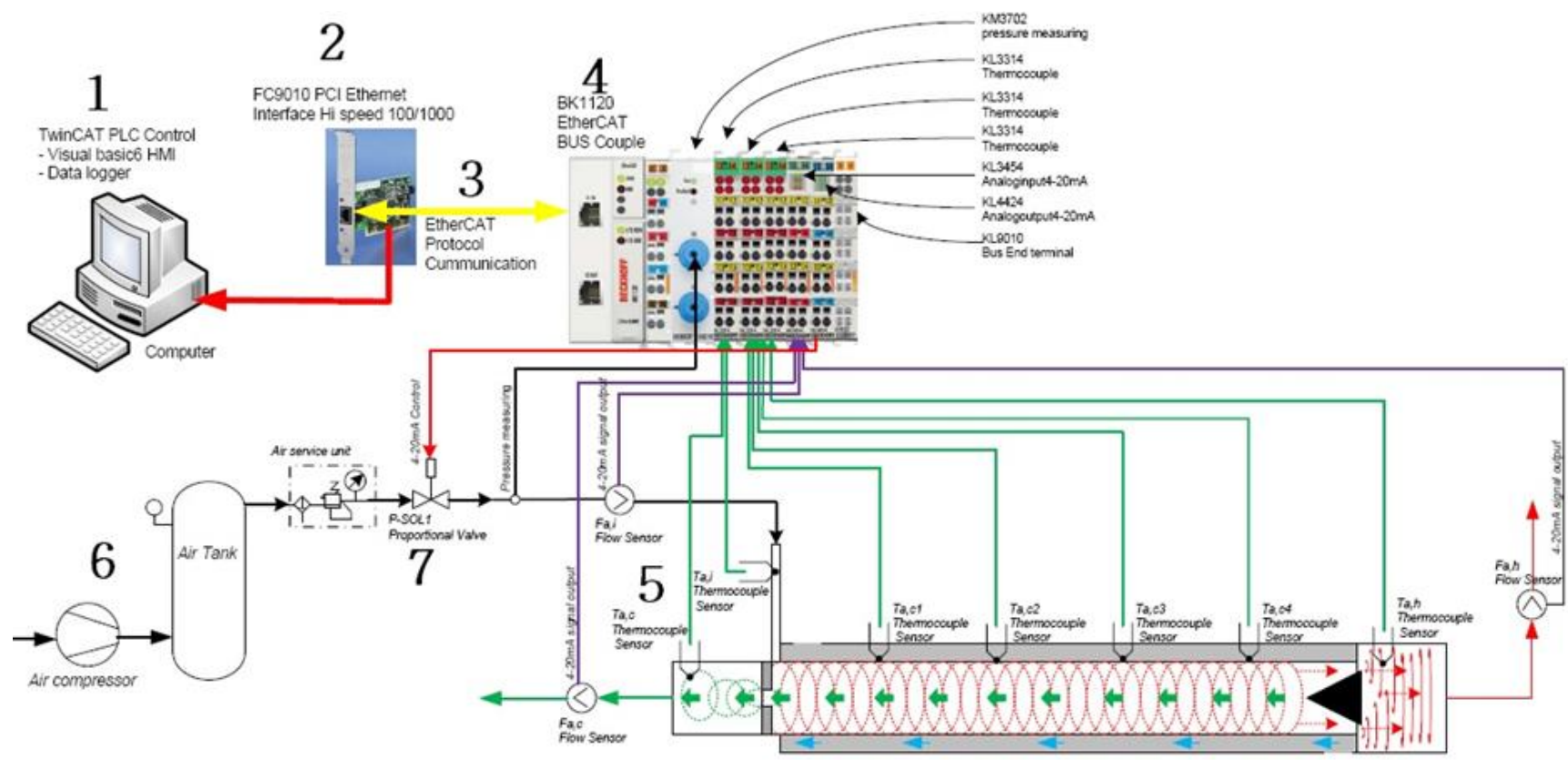

Figure 7. Performance assessment using the thermocouple

Figure 7 reveals that performance assessment for the vortex tube encompasses: No. 1 is computer twin CAT PLC control with Visual basic 6 HMI show data logger. No. 2 is FC9010 PCI Ethernet Interface Hi speed 100/1000. No. 3 is Ether CAT Protocol Communication. No. 4 is BK1120 Ether CAT BUS Couple with KM3702 pressure measuring, KL3314
Thermocouplex3, KL3454 Analog input 4-20mA and KL9010 Bus End terminal. No. 5 is Thermocouple Sensor as the testing device shown in Figure.7 and 8, the exit air temperature (Tc) was measured by only one thermocouple Sensor. No. 6 is Air compressor. No. 7 is P-SOL1 Proportional Valve, Flow Sensor $\mathrm{x} 3$.
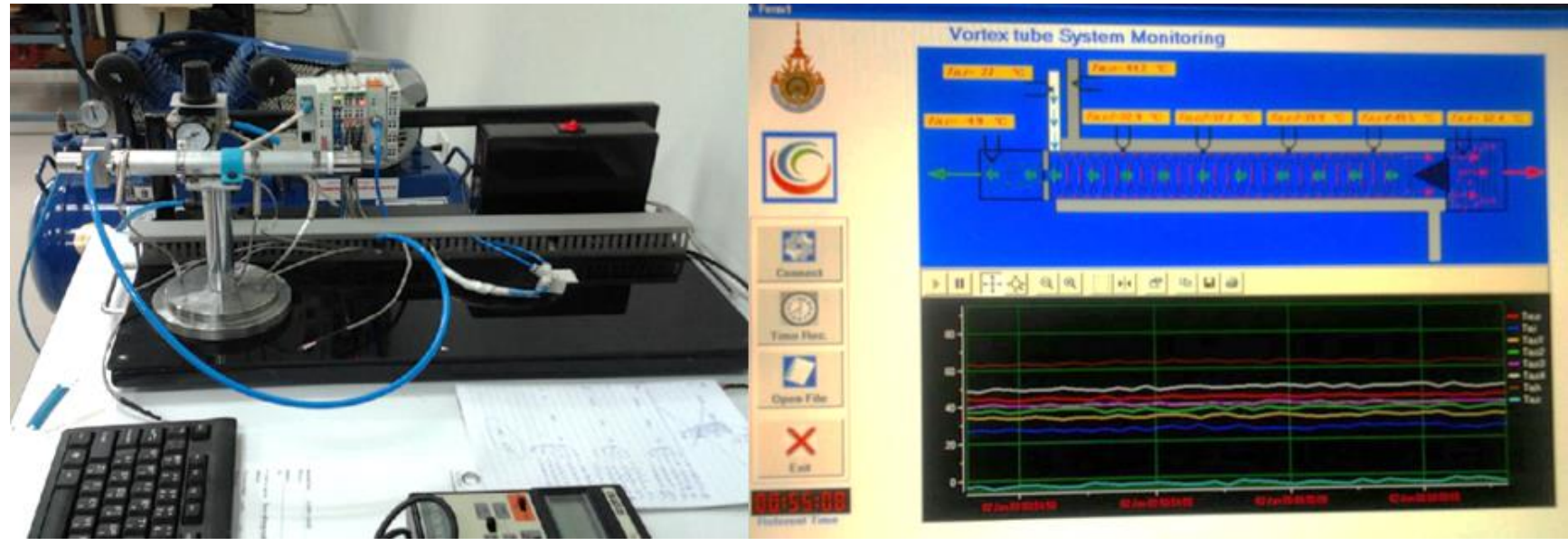

Figure 8. Experiment with the vortex tube data logger

According to Figure. 8, the data logger was designed for measuring temperature of the single snail entry vortex tube. Temperatures and airflow rates within the tube were constantly evaluated using the data logger, with records taken each minute using twin CAT PLC control under visual basic 6 HMI. Figure. 8 shows the data logger results for the inlet air temperature $\left(T_{i}\right)$, the cold air outlet temperature $\left(T_{c}\right)$, the air pressure within the tube (Bar), and the rate of inlet air flow $\left(X_{c}\right)$ [17].

\section{RESULTS AND DISCUSSION}

The vortex tube is the device that can reduce the air temperature to minus degrees Celsius, from the typical air temperature of $25{ }^{\circ} \mathrm{C}$ out from a pump or an air compressor. The process takes place when the air swirls and separates the temperatures without using any coolant substances. Heat from the outer layers is involved in the process of energy transfer with the colder stream which is found at the vortex tube's axial line, as Figure. 9 shows. 


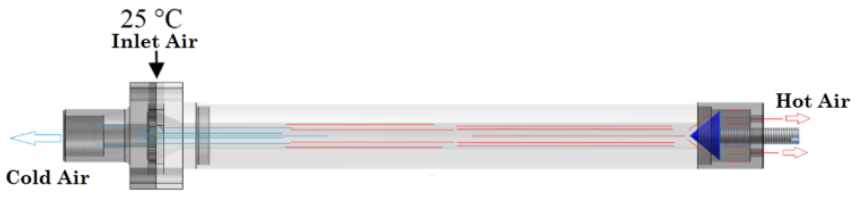

Figure 9. Vortex tube energy transfers

During this study the inlet air pressure rate for the entry was set at $\left(P_{i}\right)$ 3.0, 2.0, 1.0 Bar. The inlet air pressures is compressed through the nozzles along tangential velocities inside the vortex tube to create the movement from heavy air swirling and the shifts as the result of the air pressures that is forced through the nozzles. As the air enters the vortex tube and swirls around, the temperature at the tube's core is lower than at the entry [18]. At the tube wall, the temperature exceeds that at the inlet, so the snail entry was designed with these facts in mind in order to test the air temperature reduction efficacy using low pressure air inlet [19-20]. A Data Logger was employed to monitor the temperatures and the airflow rates, with a vortex tube length of $200 \mathrm{~mm}$, inner diameters of $10,12,14,16$ and $18 \mathrm{~mm}$, the snail nozzle entries with $4,5,6$,

7, and 8 inlet nozzles, the inlet air temperature at $25^{\circ} \mathrm{C}$ and the resulting exit air temperature as at $T_{c}{ }^{\circ} \mathrm{C}$.

The experiment on the use of the device and the measurement of the air temperature while entering into the vortex tube by thermocouple can be illustrated in the data logger. An experiment was conducted to examine the inner part of the tube, establishing the air temperatures at the inlet and at the cold air outlet via the orifice [21]. The results were then compared for tests using different numbers of nozzles (4, 5, 6, 7, and 8 nozzles). Meanwhile, various different inner diameters were employed $(10,12,14,16$, and $18 \mathrm{~mm})$ in assessing the drop in cold air temperature, and the energy separation of the vortex tubes internal pressure. Each test is carried out using set air pressure values at the snail entry, while $P_{i}=3.0,2.0,1.0$ Bar. The temperature drop in the cold air is given by the equation $\Delta T_{c}=T_{i}-T_{c}$, measured at the maximum difference as indicated in Figure. 6, 7, and 8. In this study, the ratio of cold air mass compares the cold air flow rate and the intake air flow rate and is given by equation (1) $x_{c}=$ $\frac{\dot{m}_{c}}{\dot{m}_{l}}=0.4$. Compatible pairs of the devices can be described as follows: (n) 4, 5, 6, 7, and 8 inlet nozzles go with (D) 10, 12, 14,16 , and $18 \mathrm{~mm}$. inner diameter.
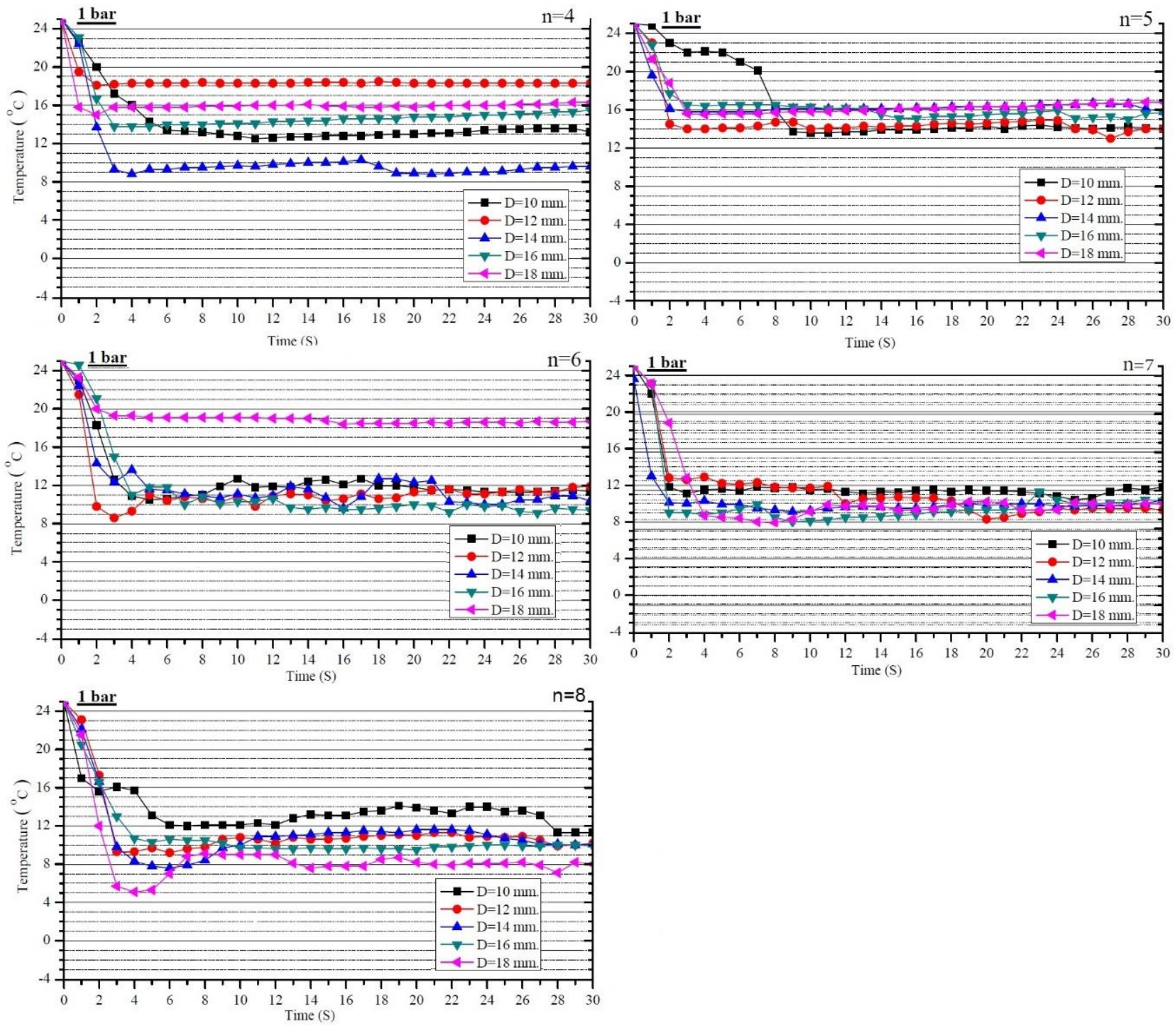

Figure 10. Experimental 1 bar for snail nozzle number in vortex tube as inlet air temperature $25^{\circ} \mathrm{C}$ 
From Figure. 10 Experimental 1 bar for snail nozzle number in vortex tube. It was discovered that (n) 8 inlet nozzles and (D) $18 \mathrm{~mm}$. inner diameter of the tube the minimum air temperature of $5.1^{\circ} \mathrm{C}$, comparing between the numbers of inlet nozzles, the length of inner diameters of the tube, as the effects towards the temperature reduction of cold air or energy
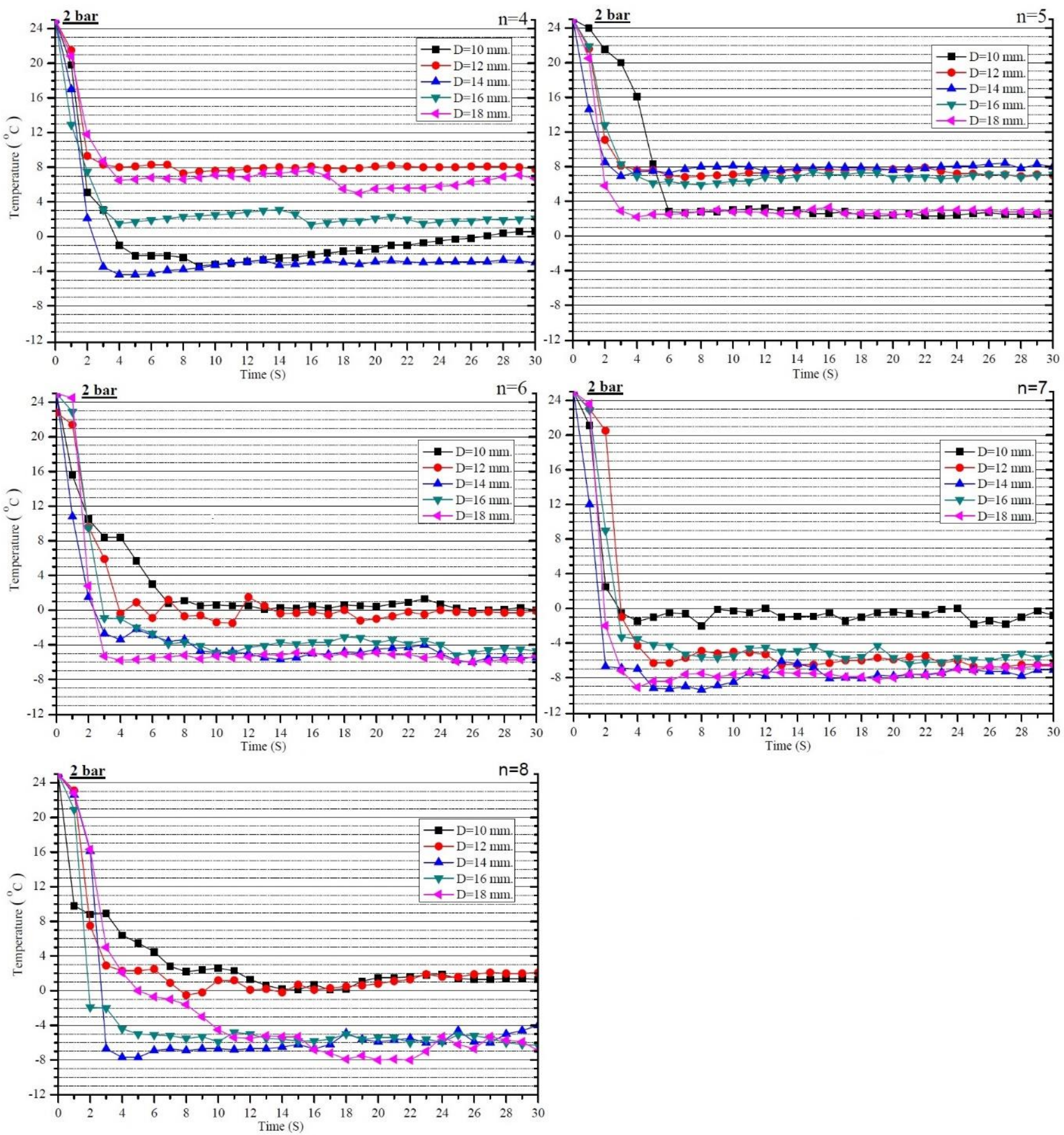

Figure 11. Experimental 2 bar for snail nozzle numbers in vortex tube as inlet air temperature $25^{\circ} \mathrm{C}$

From Figure. 11, Experimental 2 bar for snail nozzle numbers in vortex tube. It was discovered (n) 7 inlet nozzles and (D) $14 \mathrm{~mm}$. inner diameter of the vortex tube the lowest temperature of $-9.2^{\circ} \mathrm{C}$ from the comparisons across the different inlet nozzles, inner diameters of the vortex tube, as the effects to reduce the cold air temperature or energy separation occurring within the vortex tube, with the inlet air pressure fixed value set for snail entry as $P_{i} 1$ Bar. Comparing cold air temperature reductions $\left(\Delta T_{c}\right)$ gives a value of $19.9^{\circ} \mathrm{C}$ on the basis of the equation. (2). 

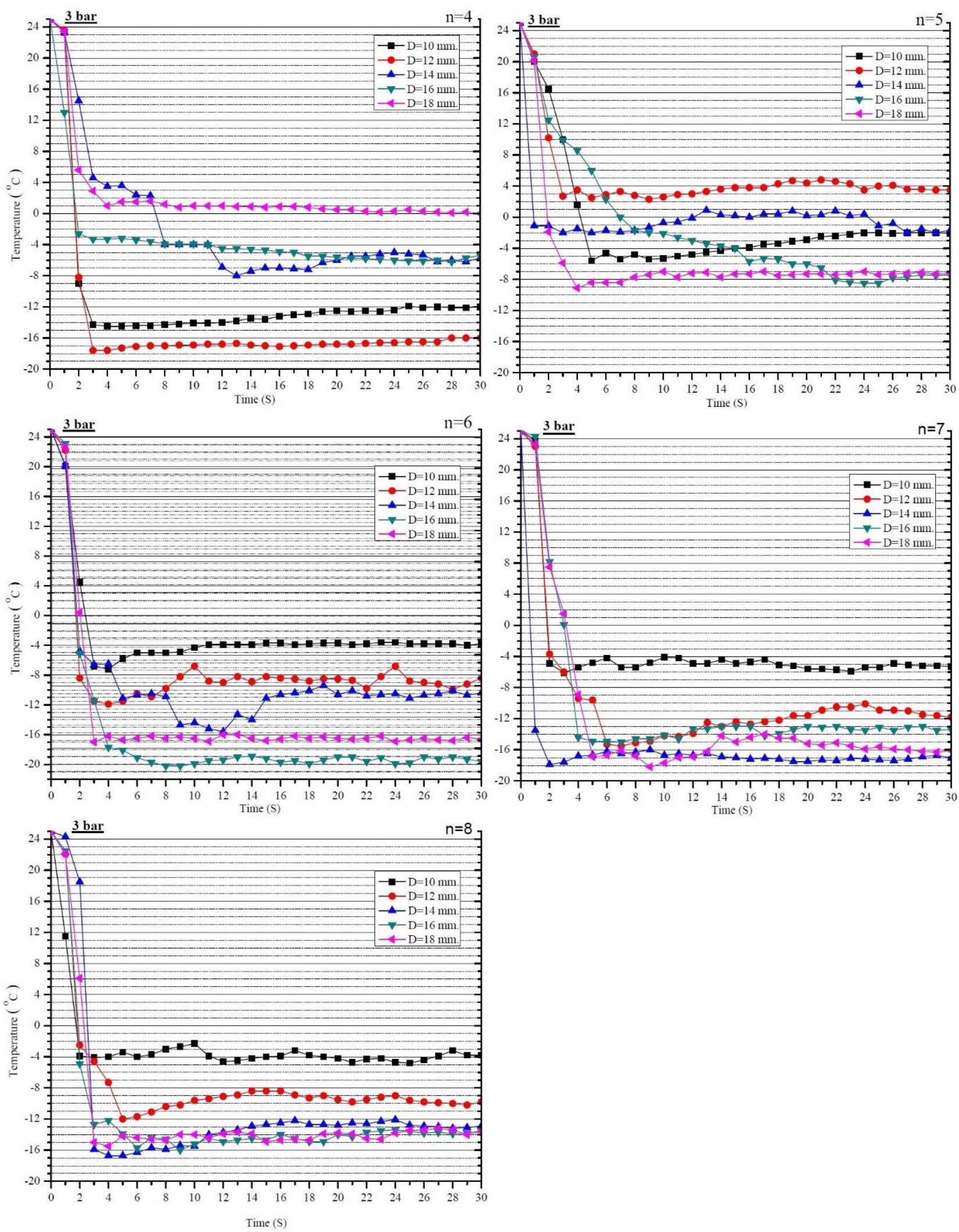

Figure 12. Experimental 3 bar for snail nozzle number in vortex tube as inlet air temperature $25^{\circ} \mathrm{C}$

Figure. 12 Experimental 3 bar for snail nozzle number in vortex tube. It was discovered (n) 6 inlet nozzles and a tube inner diameter of (D) $16 \mathrm{~mm}$. minimum temperature of $20.2^{\circ} \mathrm{C}$ when testing the influence of the various parameters related to inlet nozzles and the differing inner diameters upon reducing energy separation within the vortex tube or lowering the cold air temperature. Setting the air pressure fixed rate for snail entry at $P_{i}=3$ bars, gave the lowest temperatures, while the largest difference in terms of the reduction of cold air temperature $\left(\Delta T_{C}\right)$ was shown to be $45.2^{\circ} \mathrm{C}$ applying equation (2)

From Figure. 13, the performance comparison in the reduction of the cold air temperature according to equation (3), with inner diameters (D) 10,12, 14, 16 and $18 \mathrm{~mm}$. and snail entry nozzles number of (n) 4, 5, 6, 7 and 8 found that the air pressure at 1 bar for a vortex tube inner diameter of $18 \mathrm{~mm}$. gave a cooling efficiency $(\eta)$ of $18.3 \%$ with nozzle number (n) 8. An air pressure of 2 bars and a vortex tube inner diameter 
of (D) $14 \mathrm{~mm}$. gave a cooling efficiency $(\eta)$ 31.6\%. with nozzles number 7 . With an air pressure of 3 bars and a vortex tube inner diameter of (D) $16 \mathrm{~mm}$. and a nozzles number of (n) 6 , the cooling efficiency was $(\eta) 41.6 \%$.

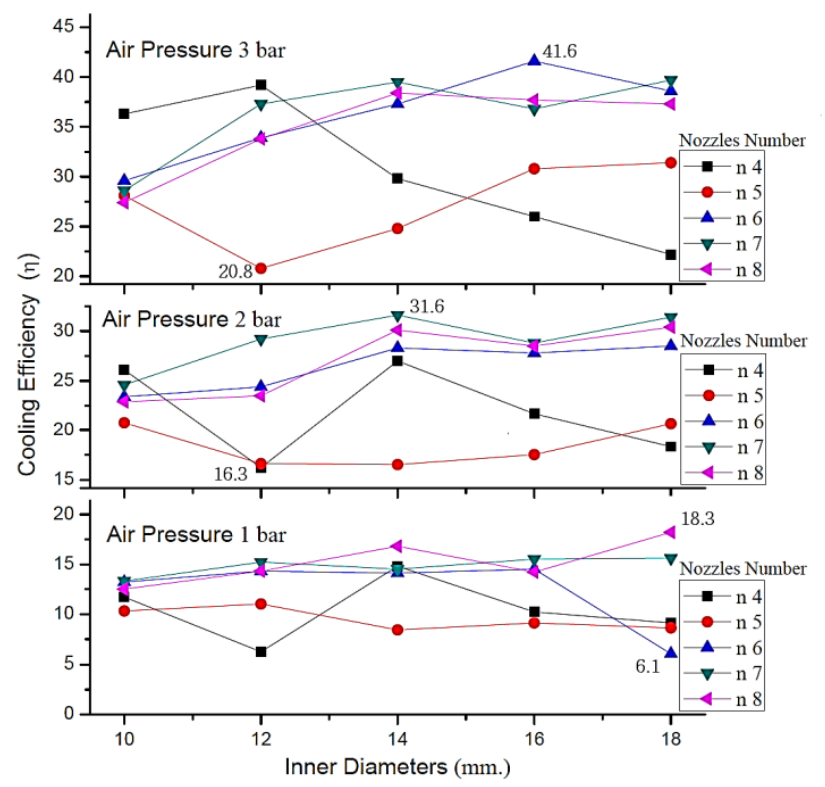

Figure 13. The influence of the number of nozzles and the inner diameter of the orifice upon the efficiency of energy flux separation cooling

\section{CONCLUSION}

This study was carried out in order to examine the influence upon thermal separation in the vortex tube by adjustments to the various parameters encompassing the inner diameters of the tube, the number of inlet nozzles, and the types of inlet air pressure. The cooling efficacy results showed that the maximum energy separation capability is achieved at the setup [22] of the outlet for cold air at 0.4 times the inlet air mass. The minimum temperature of the reduction is $-20.2^{\circ} \mathrm{C}$ at a temperature inlet of $25^{\circ} \mathrm{C}$. The maximum temperature difference $\left(\Delta T_{c}\right)$ was found to be $45.2^{\circ} \mathrm{C}$. The inlet air pressure through the snail entry is 3.0 bar with a snail entry of 6 and $18 \mathrm{~mm}$ inner diameter of the tube. The maximum cooling efficiency equation gave $(\eta)$ 41.6\%

\section{ACKNOWLEDGEMENT}

The authors are grateful to Rattanakosin College for Sustainable Energy and Environment (RCSEE), Rajamangala University of Technology Rattanakosin (RMUTR) for valuable knowledge and all educational supporting. Special thanks to The Energy Policy and Planning Office (EPPO) funding and grant support this research.

\section{REFERENCES}

[1] Thakare HR, Parekh AD. (2017). Experimental investigation \& CFD analysis of Ranque-Hilsch Vortex Tube. Energy 133: 284-298. https://doi.org/10.1016/j.energy.2017.05.070
[2] Attalla M, Ahmed H, Salem Ahmed M, El-WafaAA. (2017). Experimental investigation for thermal performance of series and parallel Ranque-Hilsch vortex tube systems. Applied Thermal Engineering 123: 327339.

https://doi.org/10.1016/j.applthermaleng.2017.05.084

[3] Cebeci I, Kirmaci V, Topcuoglu U. (2016). The effects of orifice nozzle number and nozzle made of polyamide plastic and aluminum with different inlet pressures on heating and cooling performance of counter flow Ranque-Hilsch vortex tubes: An experimental investigation. International Journal of Refrigeration 72: 140-146. https://doi.org/10.1016/j.ijrefrig.2016.07.013

[4] Eiamsa-ard S, Promvonge P. (2008). Review of RanqueHilsch effects in vortex tubes. Renewable and Sustainable Energy Reviews 12: 1822-1842. https://doi.org/10.1016/j.rser.2007.03.006

[5] Eiamsa-ard S. (2010). Experimental investigation of energy separation in a counter-flow Ranque-Hilsch vortex tube with multiple inlet snail entries. International Communications in Heat and Mass Transfer 32: 100-107. https://doi.org/10.1016/j.icheatmasstransfer.2009.09.01 3

[6] Saidi MH, Valipour MS. (2003). Experimental modeling of vortex tube refrigerator. Applied Thermal Engineering 23: 1971-1980. https://doi.org/10.1016/S13594311(03)00146-7

[7] Promvonge P, Eiamsa-ard S. (2004). Experimental investigation of temperature separation in a vortex tube refrigerator with snail entrance. Asean Journal on Science \& Technology for Development: 297- 308.

[8] Subudhi S, Sen M. (2015). Review of Ranque-Hilsch vortex tube experiment using air. Renewable and Sustainable Energy Reviews 52: 172-178. https://doi.org/10.1016/j.rser.2015.07.103

[9] Aydin O, Baki M. (2006). An experimental study on the design parameters of a counterflow vortex tube. Energy 31: $2763-2772$ https://doi.org/10.1016/j.energy.2005.11.017

[10] Bovan M, Valipour MS, Dincer K, Eiamsa-ard S. (2014). Application of response surface methodology to optimization of astandard Ranquee Hilsch vortex tube refrigerator. Applied Thermal Engineering 67: 545-553.

[11] Wisnoea W, Abd Rahmana KM, Istihatb Y, David Natarajana V. (2016). Thermofluid-acoustic analysis of a Ranque-Hilsch vortex tube. Procedia Technology 26P: 544-551. https://doi.org/10.1016/j.protcy.2016.08.068

[12] Manimaran R. (2016). Computational analysis of energy separation in a counter-flow vortex tube based on inlet shape and aspect ratio. Energy 107: 17-28. https://doi.org/10.1016/j.energy.2016.04.005

[13] Subudhi S, Sen M. (2015). Review of Ranque-Hilsch vortex tube experiments using air. Renewable and Sustainable Energy Reviews 52: 172-178. https://doi.org/10.1016/j.rser.2015.07.103

[14] Thakare HR, Parekh AD. (2014). CFD analysis of energy separation of vortex tube employing different gases, turbulence models and discretization schemes. International Journal of Heat and Mass Transfer 78: 360370 .

https://doi.org/10.1016/j.ijheatmasstransfer.2014.06.083

[15] Zhang B, Guo X, Yang Z. (2016). Analysis on the fluid flow in vortex tube with vortex periodical oscillation characteristics. International Journal of Heat and Mass 
Transfer 103: 1166-1175.

[16] Bovand M, Valipour MS, Eiamsa-ard S, Tamayol A. (2013). Numerical analysis for curved vortex tube optimization. International Communications in Heat and Mass $\quad$ Transfer $\quad 50$ : 98-107. https://doi.org/10.1016/j.icheatmasstransfer.2013.11.01 2

[17] Agrawal N, Naik SS, Gawale YP. (2014). Experimental investigation of vortex tube using natural substances. International Communications in Heat and Mass Transfer 52: 51-55. https://doi.org/10.1016/j.icheatmasstransfer.2014.01.00 9

[18] Liang Z, Luo X, Feng Y, Xu G. (2015). Experimental investigation of pressure losses in a co-rotating cavity with radial inflow employing tubed vortex reducers with varied nozzles. Experimental Thermal and Fluid Science. 66: 304-315. https://doi.org/10.1016/j.expthermflusci.2015.03.008

[19] Amiri EO. (2018). Application of computational experiments based on the response surface methodology for studying of the recirculation zone in the Y-shaped channe. Mathematical Modelling of Engineering Problems 5(3): 243-248. https://doi.org/10.18280/mmep.050317

[20] Camaraza-Medina Y, Khandy NH, Carlson KM, CruzFonticiella OM, García-Morales OF, ReyesCabrera D. (2018). Evaluation of condensation heat transfer in aircooled condenser by dominant flow criteria. Mathematical Modelling of Engineering Problems 5(2): 76-82. https://doi.org/10.18280/mmep.050204

[21] Moraveji A, Toghraie D. (2017). Computational fluid dynamics simulation of heat transfer and fluid flow characteristics in a vortex tube by considering the various parameters. International Journal of Heat and Mass

Transfer

113:

$432-443$

https://doi.org/10.1016/j.ijheatmasstransfer.2017.05.095

[22] Kolmes EJ, Geyko VI, Fisch NJ. (2017). Heat pump model for Ranque-Hilsch vortex tubes. International Journal of Heat and Mass Transfer 107: 771-777. https://doi.org/10.1016/j.ijheatmasstransfer.2016.11.072

\section{NOMENCLATURE}

n

S

L

D

d

$x$

$m$

$T$

$P$

\section{Greek symbols}

$\eta$

$\Delta$

$\gamma$

\section{Subscripts}

c

i

$\mathrm{h}$

$\mathrm{s}$

a
Snail nozzles with entries,inlet nozzles

Temperature following the isentropic expansion

Tube length, mm

The orifice tube, $\mathrm{mm}$

Inside diameter cold, mm.

Stream mass ration

Flow rate, $\mathrm{m} / \mathrm{s}$

Temperature, ${ }^{\circ} \mathrm{C}$

Inlet air pressure, bar

Cooling efficiency, \%

Cold temperature difference, ${ }^{\circ} \mathrm{C}$

Specific heat ratio

Cold stream temperature

Inlet stream temperature

Hot stream temperature

Isentropic expansion

Atmospheric pressure 